\title{
Development of Ukrainian and Global Online Education
}

\author{
Sergiy A. Kvitka ${ }^{1}$, Valentyna S. Yehorova ${ }^{2}$, Tetiana O. Chepulchenko ${ }^{2}$, \\ Mykola M. Taranenko ${ }^{2}$, Ivan S. Bakhov ${ }^{3}$, Elena L. Feshchenko ${ }^{4}$
}

${ }^{1}$ Department of Information Technology and Information Systems, Dnipropetrovsk Regional Institute of

Public Administration of National Academy for Public Administration under the President of Ukraine,

$$
\text { Dnipro, Ukraine }
$$

${ }^{2}$ Department of Public Law, Faculty of Sociology and Law, National Technical University of Ukraine "Igor Sikorsky Kyiv Polytechnic institute”, 37 Peremohy ave. Kyiv, 03056, Ukraine

${ }^{3}$ Department of English Philology and Translation, Interregional Academy of Personnel Management, 2 Frometivska str., Kyiv, 03039, Ukraine

${ }^{4}$ Pedagogical and Academical Affairs Educational and Scientific Institute of Manegment and Psychology, SIHE "University of Managment Education", 52 Sichovykh Striltsiv str., Kyiv, 04053, Ukraine

\begin{abstract}
The article enlightens the activities of the main public online educational platforms in Ukraine, their role in the modernization of education and their socio-political influence on changes in the state. Interdependence is observed between the specificity, inherent in different stages of distance education progress. Problematic issues in the field of innovative educational technologies are highlighted: socialization of students, difficulties in control of their knowledge, metacognitive monitoring of mastering the material by them etc. The degree of organization in operation of electronic cabinets is examined and other measures supposed to introduce the telecommunicative teaching means in Ukrainian higher education.
\end{abstract}

Keywords - online education, e-learning, modern education, educational innovations, web-based education, distance education, interactive pedagogy

DOI: 10.18421/TEM94-41

https://doi.org/10.18421/TEM94-41

Corresponding author: Sergiy A. Kvitka,

Dnipropetrovsk Regional Institute of Public Administration of National Academy for Public Administration under the President of Ukraine, 29 Hoholya str., Dnipro, 49044, Ukraine

Email: kvitkase@ro.ru

Received: 06 April 2020.

Revised: 17 August 2020.

Accepted: 31 August 2020.

Published: 27 November 2020.

(c) BY-NC-ND (C) 2020 Sergiy A. Kvitka et al; published by UIKTEN. This work is licensed under the Creative Commons Attribution-NonCommercial-NoDerivs 4.0 License.

The article is published with Open Access at www.temjournal.com

\section{Introduction}

From its beginning, the $21^{\text {st }}$ century became an age of active informatization of all spheres of human life. And these days, in March 2020, the coronavirus pandemic is becoming the world's largest experiment in online learning. Industry, services sector and trade are actively incorporated into the world's network Internet. Education is no exception and it requires a lot of resources: a room for educational process itself and, in some cases, for students housing, a considerable number of teaching staff, production of learning materials, availability to effectively control the training of the students, as well as to control the progress of mastering the material. A number of these issues are solved by modern online education systems.

There is a set of concepts describing onlineeducation phenomenon: e-learning, web-based learning or internet-based learning, distributed learning, computer-assisted learning, computermediated learning [1]. In essence, all of them are describing similar processes of transmission and reception of learning materials, but the frequency of their use is much lower comparing to the concept "online education" and the choice among them depends on the wish of the researches or the practitioners of this teaching method.

\section{Literature Review}

\subsection{Online Education, Previous Studies}

The problem of online education is relatively new for global and Ukrainian science as a whole. The first articles devoted to online pedagogical practices were published in the United States and Canada in the late 
1980s. They related to the first university local networks and the so-called computer-mediated communications. The book of one of online pedagogy pioneers, the Canadian researcher L. Harasim "Educational Applications of Computer Networks" [2], published in 1986, and the article by E. Kerr [3] of the same year about the principles of holding online-conferences deserve particular attention. Under the influence of these publications, such researchers as M. Brochet [4], L. Davie [5], A. Feenberg [6], D. Graddol [7] published their works on the subject. The overwhelming majority of the first studies were related to online methods of teaching foreign languages, but later the use of computers in disciplines significantly expanded.

Generally, by the end of the 1990s, researches on online education concerned the teaching methods in multimedia classrooms at educational institutions.

In 1997, the work of K. McCormack and D. Jones "Building a web-based education system" [8] was published, which provided a detailed plan to create online courses on a variety of disciplines on the basis of a web page.

Besides the obviously positive aspects of online education, western researchers identified a number of negative factors inherent in it. So in 1999 the article by N. Hara and R. Kling "Students' frustrations with a web-based distance education course" was published, where it was practically for the first time that a number of issues were raised not only about the technical difficulties, but also about the inability of online education to give a certain system of values, to take into account the individual nuances of a student, which are practically not visible at a distance, about frequent inequalities between the expected and obtained results of such training, etc. [9].

Three years earlier, the aspect of emotions and collective socialization in online education for children was enlightened in the articles by K. Oatley and S. Nundy [10].

In 1993, the theoretical work of M. G. Moore was published, where he provided the theoretical background for the most important principle of modern distance education "any time - any place", which means the ability to take classes without the restrictions of place and time both for a student and a teacher [11].

In the mid-1990s, the concept of e-learning emerged. It was considered as an integral component of hybrid education, which means a combination of the traditional presentation of learning material by the teacher and the active use of electronic devices [12].

Since the mid-2000s, pedagogical studies focused on the need to move from teacher-centered to student-centered education model by means of modern communication technologies [13].

After entering the "era of smart phones" in the first half of 2010s, this trend remains the most relevant in modern studies on online education [14].

\subsection{Online Education in Ukrainian Science}

In Ukrainian science, interest in a new type of education dates back to the mid-1990s, in particular in 1997 the guide for teachers, "Fundamentals of New Information Technologies in Education", was published, where the methodological basis for Ukrainian online education was developed. The first domestic publications on the subject were mainly devoted to the description of online pedagogical practices abroad, in particular in Canada and the USA, however, the significant accent was placed on the possibility and necessity to implement such experience in Ukraine on condition of informatization of schools, universities and households. Reforms in the Ukrainian higher education system along with joining the Bologna Process in 2005 demonstrated the relevance of the issue of mastering a larger part by students on their own, that resulted in the revival of academic discussion in this field.

\subsection{Distance Education Chronology}

The prototype of online education was the socalled distance education, the essence of which was the exchange of learning materials and results of the learned material between the student and the teacher respectively. The first mentioning of it in Europe dates back to the $\mathbf{1 8}^{\text {th }}$ century, but formally it was founded in 1836 by the University of London, which allowed sending the results of passed examinations by mail. The revolutionary, for its time, system of distance education was proposed by Isaac Pitman at the end of the 1840's. The innovation of the British researcher was to use the shorthand in communication between the object and the subject of learning. Subsequently, education by mail spread on the east coast of the United States and in Germany; in particular, in Pennsylvania a special newspaper with a training course for miners was published.

In 1873, in the United States the first training program was launched with the aid of the "Society to Encourage Studies at Home", which was founded by activists of the struggle for women's rights; respectively, the activities of this organization were also directed towards the use exclusively by women. The program was a major success since around 7,000 women throughout the country, regardless of their social and racial origin, benefited from it [15]. 
Disadvantages of the education system by mail were the duration of correspondence mailing, human and technical factors that could lead to loss of correspondence, significant costs for the option of express communication, the untimely response to difficulties or questions that arose during the educational process on both parts. After considering these disadvantages, a tendency emerged, which was to link the development of the distance education means to the evolution of telecommunication technologies. For example, educational radio programs with a clear system of self-testing the results, which were broadcast by reputable universities and colleges, became popular in the United States since the 1930s. A significant disadvantage of the radio-teaching system was the direct connection of the student's self-criticism and introspection level with the objectivity in evaluating their results without participation from outside. Nevertheless, as an option to improve the abovementioned approach to distance education, in the late 1940s, American teachers suggested to combine receiving materials by mail and broadcasting discussions on the educational topic on the radio.

In the 1960's, the radio, as a means of distance education transmission, was replaced with television [16], which due to its illustrativeness became the first significant step towards interactivity. It is important that a great interest in this type of education was showed not only by the world's highly developed countries in the form of a number of "open universities", but also, at that moment, the developing countries. For example, in China in 1979, Chinese Radio and TV Universities were established. Despite the conditions of the devastating consequences after the Cultural Revolution and the demographic and territorial specificities of the state, they were able at the same time to lay foundation for the future economic prosperity and to control ideologically the distance education process [17]. It is important to highlight that the experience of different countries with "open universities" was different. Thus, its realization in Great Britain was very successful, while its analogue suffered failure in the United States.

In the next decade, video cassettes with training courses became an integral part of distance education. The development of the Internet in the 1990's overcame the main problem of distance education - the lack of speed in interaction between the object and the subject of learning. But the ways to achieve it are often fundamentally different in various online learning systems.

\subsection{Online Education Chronology}

In general, the initial phase of online education massive spreading can be divided into two directions: creation of multimedia lecture rooms in educational institutions and creation of the first websites with educational content. The first direction was a centralized form of online education that required physical presence at specific time and place. However, since the mid-1990s on the North American continent and in Western Europe, the cost of personal computers significantly reduced, which affected their availability for people with average income. Development of the first convenient graphical shells on operating systems Windows and Macintosh eliminated the need for special and longterm training to master the skills of using a PC. In turn, it led to the rapid development of the Internet as a means for personal reception and spreading of information. Due to the events mentioned above, the individual direction in the online education development was prioritized.

With the emergence of the first truly portable devices and wireless communication technologies, online education started moving towards increasing of its mobility. Considerable progress in the development of software made the teacher depersonalized. The main emphasis was placed on the creation of intellectual algorithms that would control the individual frequency of repeating the material, raise the objectivity of the knowledge assessment system, and monitor the personal tempo of increasing the complexity of the material presentation to the student.

At the social level, online education, offering a wide range of options from completely free to affordable online courses, became a good alternative to frequently expensive classical education. They also help to prepare for the University. During the adaptation to a higher educational institution, lots of students feel the need to close their school learning gaps, to get used to the new training system, and get acquainted with the higher educational institution, its departments and the chosen field of study. A student's inability to fix their school learning gaps by themselves results in their expulsion that reaches the average rate of $9.2 \%$ in the first year of study [18].

Especially online education was facilitated by the emergence of the first networks of massive open online courses (MOOCs), in particular the Wikiversity (founded in 2006), Khan Academy (founded in 2008) [19], Coursera (founded in 2011), the platform for learning languages Duolingo (founded in 2011), etc. The popularity of online platforms is also explained by the absence of corruption risks during their passing, which is an important problem of the education field in many 
countries. The automation of such systems excludes intervention of human factor in assessing the obtained results. The MOOCs have such hybrids as Blended Learning Programs. Platforms are also used for delivery and tracking of blended learning. As for 2020 year, Most MOOCs are made by universities (Stanford - 209 courses, Massachusetts Institute of Technology - 234 courses, Harvard - 176 courses, Moscow Institute of Physics and Technology - 98 courses) but Some are made by companies, such as Microsoft - 298 courses or Google - 334 courses, organizations like IEEE - 20 courses, or the British Council-24 courses [20].

\subsection{Online Education in Ukraine}

The first interactive multimedia classrooms in Ukraine appeared in the 1960's; in particular, in specialized schools in Lviv and later in other big cities. They represented the desks with built-in remote control, where the buttons meant response variants, and the LEDs on the teacher's desk showed whether the answer was correct or incorrect. In addition to the classical board in these classrooms, there was a screen for slideshows, which were made by teachers themselves. The emergence of the first computer classrooms in Ukrainian schools enabled to start preparing the students for work in the Internet. However, a small number of computer science classes did not allow developing computer skills among the students, let alone implementing individual online education decisions. Meanwhile, in the West since the mid-1990s, computer science classes were of essential and consultative nature, since most of the households had computers allowing them to maintain and increase the level of operation with them.

Since mid-2010s in Ukraine, one of the IT market leaders, a number of domestic public projects with online courses was introduced: Prometheus, Ed Era, Open University of Maidan, which certificates validity is acknowledged by agreement with a number of employers.

These platforms' activities include:

1) courses on traditional educational disciplines;

2) unique projects aimed at changing the sociopolitical paradigm of Ukraine towards the shift from post-Soviet relics.

\section{Types of such projects:}

- courses on the decentralization reform,

- the basis of anti-corruption legislation,

- the basic principles of sorting domestic waste,

- prevention of school bullying, etc.
Often these online learning platforms are more trustworthy because they provide unbiased results, while in traditional Ukrainian educational institutions they depend on corruption risks, teacher's personal attitude, etc. Some Ukrainian-origin IT-education projects have become world leaders in their field. For example, the service "Grammarly", founded by Kyiv programmers, is the most popular online checker of spelling, punctuation and stylistic mistakes in English.

\subsection{Ukrainian System of the Student Electronic Cabinets}

In the same period, most Ukrainian universities introduced the system of the student electronic cabinets, which is one of the elements of the learning process management (LMS). The idea is that after authorization, the student will be able to pass intersession test tasks remotely in a convenient place for him for a certain period of time, and the test results are processed without teacher's participation with the help of a software. So far, this system has many disadvantages:

$\checkmark$ authorization on the site does not allow to check whether the student personally passes the online test;

$\checkmark$ the limited time to pass an online test does not exclude the use of auxiliary materials;

$\checkmark$ frequently limited opportunities to generate the proper variability of questions and answers that allow students to exchange responses;

$\checkmark$ hardware problems that arise during peak loads, which result in the reset of the online test session, non-registration of the responses, etc.;

$\checkmark$ the test nature of online control of knowledge is not always suitable for all specialties directed to obtain practical (laboratory) results;

$\checkmark$ the need to formulate the questions during online testing as precise as possible due to the lack of feedback between the student and the teacher, and the requirement for this clarity also negatively affects the variability of questions and answers generation;

$\checkmark$ the need for clear and concise interface of online testing, whose complexity negatively affects the student's speed;

$\checkmark$ frequent lack of ability among teachers to directly develop online testing that requires the involvement of an IT specialist, which badly affects the speed of critical updates in the work of the test program;

$\checkmark$ frequent lack of funding for state universities, which would allow to upgrade the software and hardware to provide stable functioning of the student's electronic cabinets. 


\section{7. "Digital illiteracy" Among Foreign and Ukrainian Teachers}

The importance of improving the metacognitive skills in teachers involved in online education is relevant. Traditional education, due to its illustrative contact, allows to recognize misunderstanding of the material by students faster and easier, while online learning is distant and the problem can become noticeable only at the final stages of passing the training course. Video lessons minimize such risks, but online testing systems can do this partially only after integrating them with artificial intelligence and complex heuristic algorithms.

In the context of digital safety, digital illiteracy is seen in the light of praxeology due to the fact that school teachers carry out preventive activities designed to minimise risk behaviours mediated by digital media [21].

Effective approaches to qualified workers' training in manner of social partnership are being implemented: in 2019, in Ukraine, $62.5 \%$ of employers had experience of social partnership with universities [22], including online programs. A necessary element in the rapid introduction of online learning at educational institutions is to create mechanisms to stimulate the development of such modern learning systems [23].

In Ukraine, there is a problem with the lack of the ability to use the latest telecommunication technologies among teachers, especially among the older generation. Therefore, pedagogical groups often have the opinion that such automation of education can lead to staff redundancies, as it happens in industry. This state of affairs is fundamentally different from the situation in the West, where they have special programs to overcome the "digital illiteracy" among teachers. It eliminates the problem of stereotypes about online education, and gives a powerful impetus for pedagogical initiatives to improve and develop the new forms of telecommunicative education.

Among the three types of interaction (learnercontent, learner-learner, learner-teacher) virtual high school students perceive learner-teacher interaction as the most motivational. Learner-teacher interaction in an online learning is carried out through real-time feedback systems, learning management systems, class discussions, emails and phone calls. Online teacher has common roles with traditional classroom teacher: pedagogical, managerial, social. Important aspects of the managerial role are monitoring students for inappropriate behaviour and maintaining academic integrity.

\subsection{Quality Electronic Textbook for Each Specialty}

An important task during the introduction of online education elements in higher education is to develop a quality electronic textbook for each specialty. The electronic edition differs in that it contains material in variety of forms: text, graphic, sound and video. Scrolling through electronic pages activates a whole chain of actions: the reader's hand, an input device (mouse, keyboard, touchpad), special reading programs which display images, promote eye training, expand the range of vision, and improve the perception of the text from the monitor screen. There are currently a large number of innovative devices based on the so-called electronic ink (e-ink): their screen parameters are ergonomically equal to traditional paper. It is also possible to read texts using e-book readers or tablet PCs [24]. Also, it is possible to include the elements of control of the the learning in the electronic textbook. However, solving this task requires solving a number of issues: whether this textbook should be linked to a specific environment of implementation (a web site or a special program on a stationary computer) or be cross-platform, which will allow it to function fully autonomous on many devices.

\subsection{Versatility of Online Learning Platforms}

Another disputable and problematic aspect of online education is the expediency of online learning platforms to be universal. The issue is difficult because students may have different training priorities, different ages, country of origin, even political views. According to A.W. Bates, "the diversity of students is rapidly growing" [25], therefore the future online pedagogy practitioners will need to deliberate on the diversification of online educational platforms to reasonably consider the peculiarities of some students.

\subsection{False Information Problem}

The Internet as a free space also bears the risks of the possibility of spreading false information. The opportunity to create an online learning platform by yourself becomes easier every year, but in turn it can lead to the spreading of network services with low quality education. Already, online public platforms pay much attention to convince the future users in credibility of the provided learning material. This is done by participating in the courses' development of the specialists, well known in a certain discipline, and various kinds of support from international foundations and organizations. 


\section{Conclusions}

Online education becomes an integral part of today's society in the world and in Ukraine as a quick and affordable way to get new, and most important, applied knowledge in a convenient place and time. And the only way of learning in the pandemic situation.

Online learning as a globalization product contributes to the intensification of globalization processes by unifying the educational programs and approaches in online courses and by creating conditions for the formation of the international labor market of highly qualified specialists.

Ukraine has relatively recently joined this educational trend of highly developed countries, but has intensively started to implement it in practice, both at the level of higher education and in the form of free online platforms. Some Ukrainian-origin projects have become a real-world breakthrough.

Online education has a number of problematic and yet completely unresolved aspects that distinguish it qualitatively from traditional forms of education. Without doubt, the latest technologies in the form of artificial intelligence and heuristic algorithms will be able to smooth these problems in the future.

The most optimal way to introduce online education in educational institutions is to combine its strengths, such as objectivity, interactivity, with traditional educational approaches that have greater socialization and metacognitive potential.

To successfully implement the online pedagogical practices in Ukraine, it is necessary:

- to create mechanisms to stimulate the transition to the latest educational technologies;

- to maintain proper funding both from the state budget and with the aid of investments;

- to overcome the "digital illiteracy" among the teaching staff and the general population.

\section{References}

[1]. Joksimović, S., Kovanović, V., Skrypnyk, O., Gašević, D., Dawson, S., \& Siemens, G. (2015). The history and state of online learning. Preparing for the Digital University, 93-122.

[2]. Harasim, L., \& Johnson, E. M. (1986). Educational Applications of Computer Networks for Teachers/Trainers in Ontario. Education and Technology Series.

[3]. Kerr, E. B. (1986). Electronic leadership: A guide to moderating online conferences. IEEE transactions on professional communication, (1), 12-18.

[4]. Brochet, M. G. (1986, September). Effective moderation of computer conferences-notes and suggestions. In Proceedings of the 14th annual ACM SIGUCCS conference on User services: setting the direction (pp. 377-385).

[5]. Davie, L. (1989). Facilitation techniques for the online tutor. Mindweave: Communication, computers and distance education, 74-85.

[6]. Feenberg, A. (1989). The written world: On the theory and practice of computer conferencing. Mindweave: Communication, computers, and distance education, 22-39.

[7]. Graddol, D. (1989). Some CMC discourse properties and their educational significance. Mindweave, 236241.

[8]. McCormack, C., \& Jones, D. (1997). Building a web-based education system. John Wiley \& Sons, Inc..

[9]. Hara, N., \& Kling, R. (1999). Students' frustrations with a web-based distance education course. First Monda, 4(12).

[10]. Oatley, K., \& Nundy, S. (1996). Rethinking the role of emotions in education. The handbook of education and human development: New models of learning, teaching and schooling, 257-274.

[11]. Moore, M. G. (1993). Theory of transactional distance. Theoretical principles of distance education, 1, 22-38.

[12]. Garrison, D. R. (2011). E-learning in the 21st century: A framework for research and practice. Taylor \& Francis.

[13]. Peterson, D. S. (2008). A meta-analytic study of adult self-directed learning and online nursing education: A review of research from 1995 to 2007 (Doctoral dissertation, Capella University).

[14]. Koch, L. F. (2014). The nursing educator's role in elearning: A literature review. Nurse education today, 34(11), 1382-1387.

[15]. Bergmann, H. F. (2001). " The Silent University": The Society to Encourage Studies at Home, 18731897. The New England Quarterly, 74(3), 447-477.

[16]. Ahern, T. C., \& Repman, J. (1994). The effects of technology on online education. Journal of Research on Computing in Education, 26(4), 537-546.

[17]. Wei, R. (1997). China's Radio \& TV Universities and the British Open University: a comparative perspective. 
[18]. Bochkareva, T. N., Akhmetshin, E. M., Korotkova, A. L., Lyitkina, N. L., Nasipov, I. S., \& Khaliullina, A. G. (2017). Research of students' cognitive activity. Revista ESPACIOS, 38(60).

[19]. Kaplan, D. A. (2010). EDUCATION Bill Gates' Favorite Teacher. Fortune, 162(4), 71.

[20]. Cronje, J. C. (2020). Towards a New Definition of Blended Learning. Electronic Journal of $e$ Learning, 18(2), 114-121.

[21]. Tomczyk, Ł. (2020). Skills in the area of digital safety as a key component of digital literacy among teachers. Education and Information Technologies, 25(1), 471-486.

[22]. Lysytsia, N., Martynenko, M., Bielikova, N., Gron, O., \& Us, M. (2019). Directions of social partnership of employers and universities in the sphere of economic education in Ukraine. Entrepreneurship and Sustainability Issues, 7(1), 336-352.
[23]. Zhang, Y., \& Lin, C. H. (2020). Student interaction and the role of the teacher in a state virtual high school: what predicts online learning satisfaction?. Technology, Pedagogy and Education, 29(1), 57-71.

[24]. Dolzhikova, A., Kurilenko, V., Biryukova, Y., Glazova, O., Arzumanova, R., \& Obstaravacia, S. V. (2018). Translation-oriented reading of scientifictechnical texts vs ordinary reading: Psychological and psycholinguistic aspects. XLinguae,11(2), 2433.

[25]. Bates, A. W., \& Bates, T. (2005). Technology, elearning and distance education. Psychology Press. 